\title{
Sonic Hedgehog Is a Member of the Hh/DD-Peptidase Family That Spans the Eukaryotic and Bacterial Domains of Life
}

\author{
Henk Roelink ${ }^{(D)}$ \\ Department of Molecular and Cell Biology, University of California, 16 Barker Hall, 3204, \\ Berkeley, CA 94720, USA; Roelink@berkeley.edu; Tel.: +510-642-5126
}

Received: 11 May 2018; Accepted: 7 June 2018; Published: 8 June 2018

\begin{abstract}
Sonic Hedgehog (Shh) coordinates $\mathrm{Zn}^{2+}$ in a manner that resembles that of peptidases. The ability of Shh to undergo autoproteolytic processing is impaired in mutants that affect the $\mathrm{Zn}^{2+}$ coordination, while mutating residues essential for catalytic activity results in more stable forms of Shh. The residues involved in $\mathrm{Zn}^{2+}$ coordination in Shh are found to be mutated in some individuals with the congenital birth defect holoprosencephaly, demonstrating their importance in development. Highly conserved Shh domains are found in parts of some bacterial proteins that are members of the larger family of DD-peptidases, supporting the notion that Shh acts as a peptidase. Whereas this $\mathrm{Hh} / \mathrm{DD}$-peptidase motif is present in Hedgehog $(\mathrm{Hh})$ proteins of nearly all animals, it is not present in Drosophila $\mathrm{Hh}$, indicating that $\mathrm{Hh}$ signaling in fruit flies is derived, and perhaps not a good model for vertebrate Shh signaling. A sequence analysis of Hh proteins and their possible evolutionary precursors suggests that the evolution of modern $\mathrm{Hh}$ might have involved horizontal transfer of a bacterial gene coding of a Hh/DD-peptidase into a Cnidarian ancestor, recombining to give rise to modern Hh.
\end{abstract}

Keywords: Sonic Hedgehog; bacterial Hedgehog; Drosophila Hedgehog; $\mathrm{Zn}^{2+}$ peptidase; DD-peptidase; Hedgehog evolution

\section{The Sonic Hedgehog Pro-Protein Gives Rise to the Mature Ligand after an Autoproteolytic Cleavage Event}

The Hedgehog $(H h)$ gene was first identified in the now famous developmental Drosophila melanogaster screen performed by Christiane Nüsslein-Volhard and Eric Wieshaus in the late 1970s. The screen used a technique known as "saturation mutagenesis" to isolate the genes involved in the formation of the Drosophila body plan [1]. Hh mutant larvae have a solid lawn of denticles on the cuticle rather than stripes of denticles on the anterior half of each segment, hence the name "hedgehog". Like other segment polarity genes found in this screen, Hh genes are also widely conserved among animals, and mammals have three Hh paralogs (Sonic, Indian, and Desert Hedgehog) that, like in Drosophila, play central roles in development [2].

Sonic Hedgehog (Shh) coordinates a $\mathrm{Zn}^{2+}$ metal ion with H141, D148, and H183 (mouse numbering, Figure 1) residues that are typical for $\mathrm{Zn}^{2+}$ peptidases [3], such as the bacterial peptidase, thermolysin [4]. Like many peptidases, the Shh undergoes an intramolecular auto-processing reaction resulting in cleavage between G198 and C199. As a consequence of this cleavage event, the $\mathrm{N}$-terminal product of this cleavage $(\mathrm{ShhN})$, is modified with cholesterol $[5,6]$. Subsequently Shh is modified by N-terminal acylation [7-9], rendering $\mathrm{ShhN}_{\text {chol }}$ obligatory membrane bound. Secretion of this form of Shh requires Disp1and Scube2 [10] and ADAM-type metalloproteases, yielding a form that is stripped of its lipid modifications and active in signaling [11,12] (Figure 1). 
Whereas ShhN harbors the $\mathrm{Zn}^{2+}$ peptidase motif, the carboxyterminal domain has similarities to self-splicing bacterial inteins [13]. These inteins typically cleave before a cysteine residue through the resolution of a thio-ester intermediate [6]. The G198/C199 site of cleavage is consistent with this idea. Single amino acid changes in C-terminal domains can prevent auto-processing, resulting in the perdurance of the Shh pro-protein [14]. Similarly, mutations of the residues that directly mediate $\mathrm{Zn}^{2+}$ coordination prevent the autoproteolytic processing of the Shh [15] and thermolysin pro-proteins [16]. There thus appear to be structural requirements in both the ShhC and ShhN domains for auto-processing to proceed, perhaps indicating that overlapping/complementary endopeptidase activities associated with the $\mathrm{ShhN}$ and $-\mathrm{C}$ domains are involved in autocatalytic processing. The inherent endopeptidase activity of Shh is coupled to the addition of a cholesterol moiety to $\mathrm{ShhN}\left(\mathrm{ShhN}_{\mathrm{Chol})}\right)$, which affects the distribution of the ligand [17]. Interestingly, many of the $\mathrm{Zn}^{2+}$ peptidase catalytic residues are not required for signaling by ShhN [18], and consequently, the $\mathrm{Zn}^{2+}$ coordination domain of Shh has been referred to as the "pseudo active" site $[19,20]$. Nevertheless, the importance of the $\mathrm{Zn}^{2+}$ coordination domain has become apparent as mutations of this domain have been associated with congenital malformations, demonstrating their role in development.

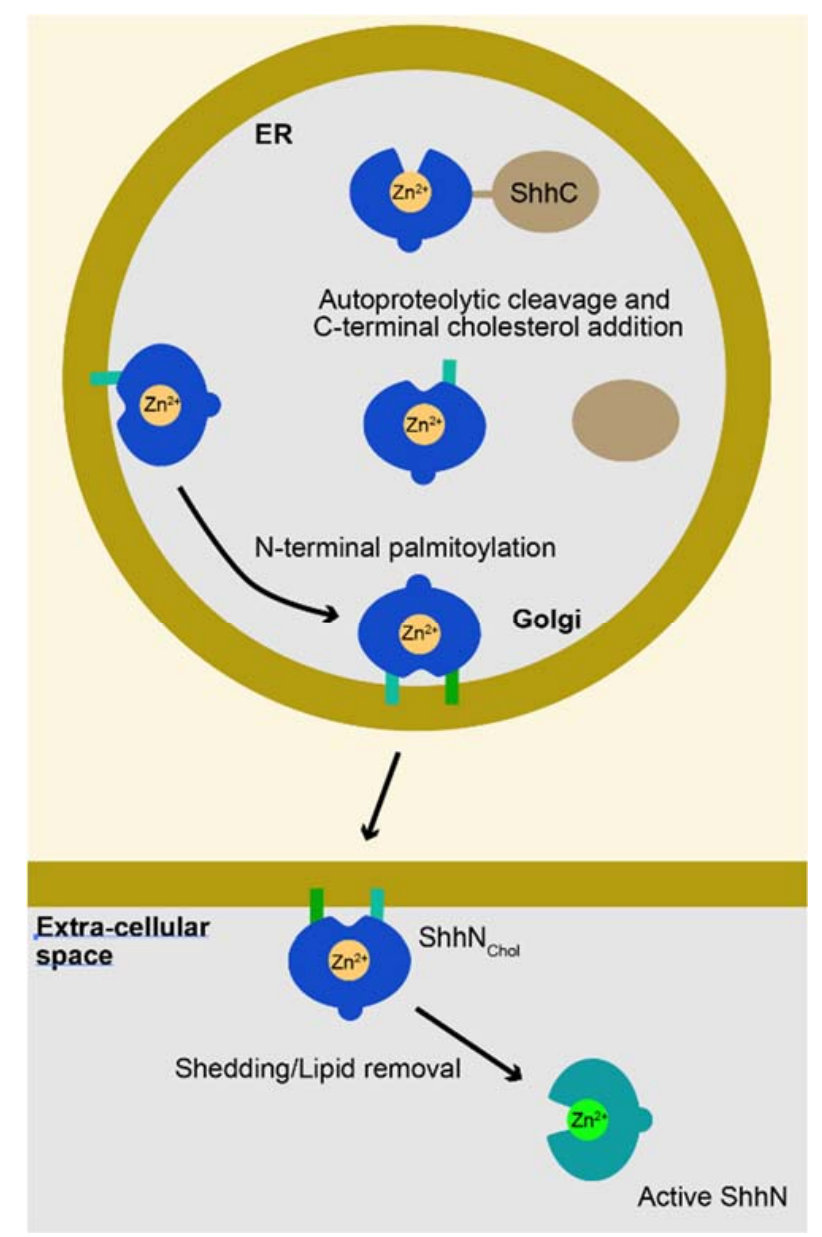

Figure 1. Diagram of the Sonic Hedgehog (Shh) processing/maturation steps. Shh is translated into a pro-protein, consisting of a ShhN and ShhC domain, that undergoes an autoproteolytic processing event prior to entry into the Golgi. This results in the attachment of a cholesterol moiety to the ShhN domain, likely shielding the $\mathrm{Zn}^{2+}$ coordination domain. In the Golgi, ShhN $\mathrm{N}_{\text {chol }}$ is further lipidated by a palmitoyl chain (green bars), further forcing its membrane association. Release and shedding are regulated processes involving Disp1, Scube2 and ADAM metalloproteases, resulting in the release of Shh devoid of its lipid moieties, with its $\mathrm{Zn}^{2+}$ coordination domain exposed. 


\section{Both the N- and C-Terminal Domains of Shh Are the Targets for Point Mutations Found in Holoprosencephaly}

SHH mutations are commonly found in holoprosencephaly, a congenital syndrome that can be caused by aberrant Shh signaling [21-23] (Figure 2C). Single amino acid substitutions can be found in both the $\mathrm{N}$ - and C-domains of the Shh pro-protein but are more prevalent in ShhN $\left(40 / 181\right.$ in $\mathrm{N}, 38 / 266$ in $\left.\mathrm{C}, \mathrm{Z}=-3.6, p=3.2 \times 10^{-4}\right)$. Two of the $\mathrm{Zn}^{2+}$ coordination residues (H140 and D147 (Figure 2C, blue)), have been found to be mutated in holoprosencephalic individuals, indicating that they are required for normal Shh function, consistent with the notion that the putative peptidase activity of Shh is important for signaling. The D148 equivalent is not conserved in Drosophila $\mathrm{Hh}$, indicating it is not required for binding to Ptch. Traiffort et al. showed that Shh-H140P fails to undergo auto-processing, and was detected only as the Shh pro-protein [15]. This indicates that the perdurance of the Shh pro-protein might contribute to holoprosencephaly. It further shows that the correct $\mathrm{Zn}^{2+}$ coordination is necessary for processing the Shh pro-protein into $S h h N_{C h o l}$. The face of ShhN opposite to the $\mathrm{Zn}^{2+}$ coordination domain is dominated by a large $\alpha$-helix (Figure 2A). This helix is enriched in point mutations found in holoprosencephalic individuals (Figure 2C, dark green). Two tested mutations, SHH-W117G and W117R, were unable to undergo auto-processing [15], further emphasizing the structural requirements of the N-domain in auto-processing. Similarly, several mutations in the C-terminal domain prevent processing [14,15], emphasizing the central role that this domain plays in processing the Shh pro-protein. The Shh mutations found in holoprosencephaly that thus likely affect Shh function indicate critical roles for both the N-terminal and C-terminal domains in auto-processing, leaving the precise mechanisms and events by which the Shh pro-protein matures unresolved.

A

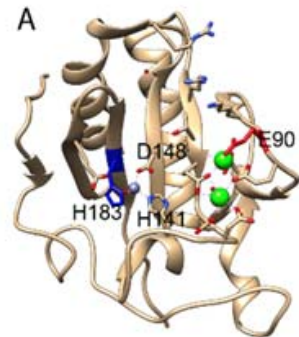

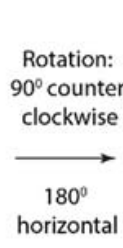

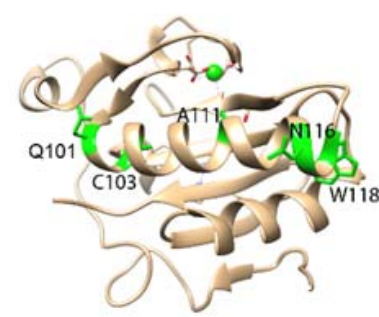

B

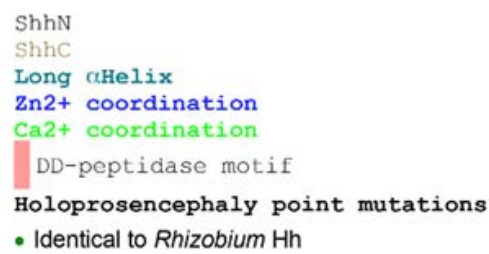

C $\mathrm{Y}$
MLLLLARCELVILASSLLVCPGLACGPGRGFGKRRHPKKLTPLAYKQEI PNVAEKTLGASGRYEGKITRNSERFKELTPNYNPDI IFKDEENTGADRLMT

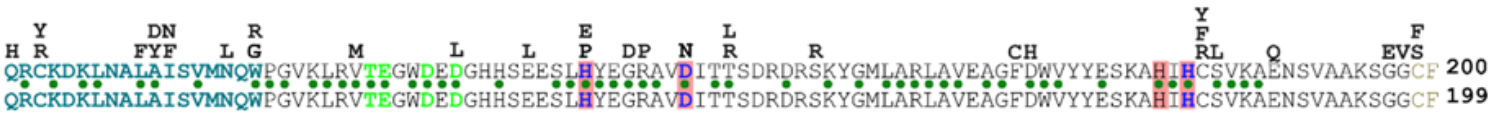

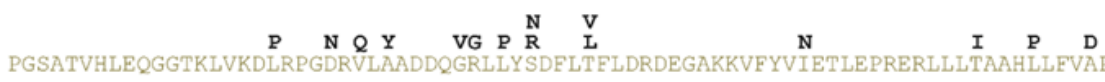

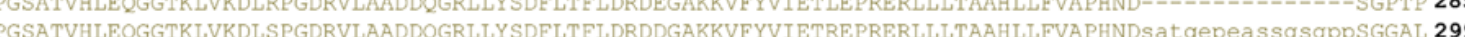

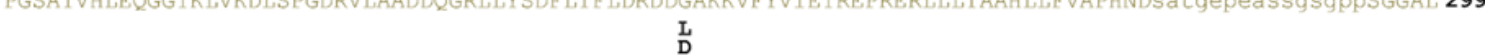
L
VR
Y LYC

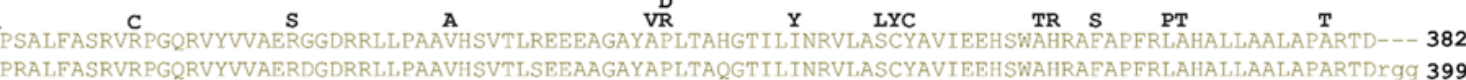

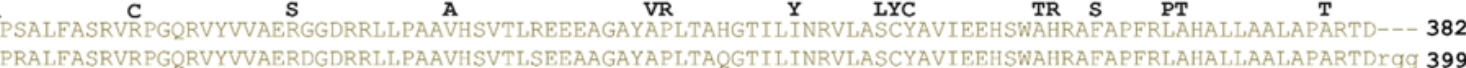

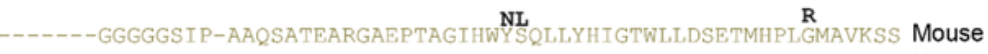

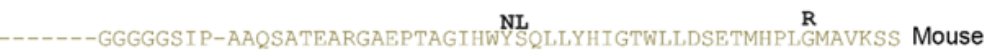
dsgggdrGGGGGVAITAPGAADAPGAGATAGIHWYSQLLYQIGTWLLDSEALHPLGMAVKSS Human

Figure 2. Salient features of the Shh protein. (A) Crystal structure of ShhN. The $\mathrm{Zn}^{2+}$ (steel) and $\mathrm{Ca}^{2+}$ (green) coordination domains are indicated. Residues in the large $\alpha$-helix mutated in holoprosencephaly are labeled in green. (B) Legend. (C) Lineup of mouse Shh (top) and human (bottom) Shh. Point mutations resulting in single amino acid changes in Shh found in holoprosencephalic individuals are shown above the lineup. Residues mediating $\mathrm{Ca}^{2+}$ and $\mathrm{Zn}^{2+}$ coordination are labeled in blue and green respectively. Green dots indicate conserved residues between Rhizobium $\mathrm{Hh}$ and mouse/human Shh. 


\section{Shh Has All the Hallmarks of a DD-Peptidase}

The notion that Shhs are pseudo-proteases is primarily based on studies claiming that the $\mathrm{Zn}^{2+}$ coordination site is required to maintain the correct and stable Shh structure and for Shh to bind to Ptch1 [24], but it does not mediate protease activity [18]. This rejection of the Shh protease function was based one experiment with a negative outcome, which used simple biochemical assays using artificial peptide substrates, common peptidase inhibitors, and E. coli expressed non-lipidated ShhN mutants that were not derived from the Shh pro-protein. Under such experimental conditions, even testing established proteases would possibly fail to reveal their proteolytic activities. A possibly more useful approach would be to more precisely determine the effects of Robotnikinin, a small molecule that binds to the Shh $\mathrm{Zn}^{2+}$ coordinating domain [25] at high nanomolar concentrations [26], in cells that lack Ptch function.

In $\mathrm{Zn}^{2+}$ peptidases, the E177 equivalent abstracts a proton from the catalytic water at the $\mathrm{Zn}^{2+}$ coordination domain, which is followed by a nucleophilic attack of the $\mathrm{OH}^{-}$on the peptide backbone. Shh-E177A is, therefore, predicted to be impaired for the intrinsic $\mathrm{Zn}^{2+}$ peptidase activity. Analysis of this mutant has revealed two interesting properties. First, Shh-E177A is unable to mediate signaling from the notochord to the overlying neural tube (in trans), but is more capable than Shh of inducing the $\mathrm{Hh}$ response when expressed in the developing neural tube (likely in cis) [27]. Second, purified ShhN-E177A is more stable in solution than ShhN, indicating a cannibalistic peptidase activity that is intrinsic to ShhN. This activity is inhibited by the binding of one or two $\mathrm{Ca}^{2+}$ ions [4] to ShhN (Figure 2A), using a binding motif that is conserved among $\mathrm{Hh}$ proteins and present in thermolysin. It appears that interfering with the putative $\mathrm{Zn}^{2+}$ peptidase activity either via the $\mathrm{Zn}^{2+}$ coordination domain or E177 has negative consequences for Shh signaling during development, indicating a role for this peptidase activity-associated residue for normal Shh function.

The conservation of the $\mathrm{Zn}^{2+}$ coordinating, $\mathrm{Ca}^{2+}$ coordinating and other catalytic residues throughout evolution supports the possibility that Hhs are not pseudo-proteases but, the properly matured form with the endogenous substrate, may indeed act as peptidases. Furthermore, a structural analysis of interactions between Shh and its Hh interacting protein (Hhip) showed that they resemble molecular interactions between matrix metalloproteases (MMPs) and the tissue inhibitor of metalloproteinase (TIMP). In both cases, a loop present in Hhip and TIMP interacts closely with the ShhN-coordinated $\mathrm{Zn}^{2+}$, thus blocking catalytic activity. This striking similarity between unrelated protease/inhibitor pairs further supports the notion that $\mathrm{ShhN}$ is a $\mathrm{Zn}^{2+}$ peptidase; not only is an active site present, but interactions of this site with Hhip and possibly, Ptch1 also resemble established metalloprotease/inhibitor interactions [19].

As is typical for a protease active site, the $\mathrm{Zn}^{2+}$ in $\mathrm{ShhN}$ sits at the bottom of a cleft and is exposed to solvent and not hidden inside of the molecule. This configuration is conserved in the mature form of the well-characterized protease, thermolysin [3]. ShhN homologs in bacteria are characterized by a conserved $\mathrm{Zn}^{2+}$ coordination motif which defines a family of prokaryotic proteins that are characterized by the DD-peptidase fold [28]. The signature peptidase fold is a central, five-stranded, antiparallel $\beta$-sheet, separating the $\mathrm{Zn}^{2+}$ coordination domain from several $\alpha$-helices, as found in ShhN (Figure 2A). Members of this family include murein endopeptidase (penicillin resistant enzymes) and peptidase M15 (bacterial D-alanyl-D-alanine carboxypeptidases (DD-peptidase), the target for penicillin) [28]. Both these peptidases play critical roles in bacterial cell wall modification. Shh and peptidase M15 share the two histidine residues and an aspartic acid residue that mediate $\mathrm{Zn}^{2+}$ coordination (H141 D148, $\mathrm{H} 183$ for Shh). The overall $\mathrm{Zn}^{2+}$ coordination motif is also found in lysostaphin, another peptidase that cleaves peptide bonds in bacterial peptidoglycan, and is referred to as the "LAS" (lysostaphin, D-alanyl-D-alanine carboxypeptidase, Shh) arrangement [29]. DD-peptidases characteristically contain an $\mathrm{H}-\mathrm{X}(6)-\mathrm{D}$ and an $\mathrm{H}-\mathrm{X}-\mathrm{H}$ motif that coordinate $\mathrm{Zn}^{2+}$ into an accessible catalytic cleft. Based on all of these criteria, Shh is a member of this class of peptidases [28], further supporting the notion that Shh can function as a protease, perhaps even targeting a glycoprotein. Characterized bacterial DD-peptidases use a catalytic mechanism in which the acyl-linked peptide-enzyme intermediate is resolved by a 
nucleophilic attack of the adjacent peptidoglycan chain, thus cross-linking the peptidoglycan chains in the bacterial cell wall, and it remains to be determined if Shh has a similar activity.

\section{Several Bacterial Species Have Highly Conserved HhN Domains}

Remarkably, several species of bacteria carry highly conserved Hedgehog proteins with unknown function (Figures 3 and 4 and Supplementary file). An approximately 145 amino acid domain comprising the bulk of ShhN (Figure 3, green box) and containing the typical DD-peptidase motif has over $50 \%$ identity to some bacterial proteins (Figure 4B), and this class of protein domains will be referred to as bacHhs. All the residues involved in $\mathrm{Zn}^{2+}$ and $\mathrm{Ca}^{2+}$ coordination are identical, as is E177, a residue required for non-autonomous Shh signaling. In bacteria, the Hh/DD-peptidases domain is the $\mathrm{C}$-terminal part of larger proteins. Homologs of the $\mathrm{N}$-terminal domains of the bacterial Hh proteins can be found to be associated with different subtypes of $\mathrm{Zn}^{2+}$ peptidases throughout bacteria (Figure 4A). In a few bacterial species, including some Rhizobium and Bradyrhizobium species, the N-terminal part preceding the Hh/DD-peptidase domain is predicted to contain three transmembrane regions, placing the Hh domain in the periplasmic space (Figure 4A). In this configuration, the third transmembrane domain of Rhizobium bacHh lines up perfectly with the signal sequence of Shh. No clear homologs of the Hh receptors, Patched and Smoothened, are present in any of these bacteria, or their Rhizobium Legume hosts, further supporting the idea that bacHhs serve as peptidases, rather than as ligands. The similarity of ShhN to its bacterial counterparts is as high as to other distant metazoan Hhs, and higher than its similarity to the Cnidarian hedgling N-domain and Drosophila HhN (Figure 4B). Given the high degree of similarity between Shh and its bacterial counterparts, it is likely that they share a specific function. The relatively small number of sequenced bacteria with a highly conserved HhN domain (I found about a dozen) do not share any obvious characteristics or ecological niches, and the precise function of this bacHh peptidase activity remains unknown.

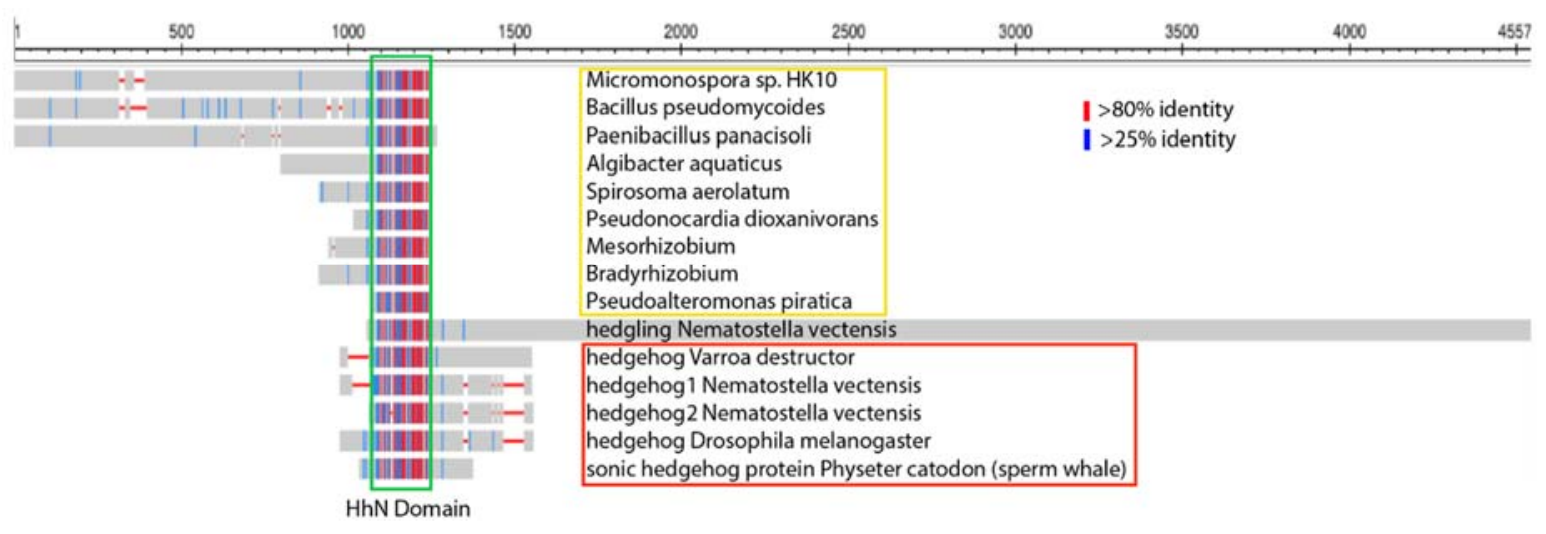

Figure 3. HhN domains are present in bacteria. Lineup of several hypothetical proteins in bacteria, Hedgling and metazoan Hhs. The conserved domain ( $\mathrm{HhN}$, green box, about 175 residues) is flanked by other sequences in the various species. In bacteria (yellow box) the $\mathrm{HhN}$ domain is the C-terminal end of the hypothetical proteins. The HhN domain is the N-terminal part of Hedgling and Hhs (red box). The blue and red lines indicate medium and high levels of conservation. Accession numbers of the aligned proteins are in the Supplementary file. 
A

\begin{tabular}{|c|c|c|}
\hline \multirow{3}{*}{$\begin{array}{l}\text { Common } \mathrm{N} \text {-terminal Domain } \\
\text { found in eubacteria }\end{array}$} & $\mathrm{Zn}^{2+}$ peptidases & \multirow[b]{2}{*}{ Cell wall hydrolase activator } \\
\hline & Peptidase M23 & \\
\hline & Peptidase C39 & Cell wall synthesis \\
\hline \multirow[b]{2}{*}{ Transmembrame domain/signal sequence } & Peptidase C70 & Cysteine protease \\
\hline & bacHhN & \multirow{2}{*}{$\begin{array}{l}\text { Hh/DD-peptidase } \\
\text { superfamily }\end{array}$} \\
\hline $\begin{array}{l}\text { Rhizobium-type } \mathrm{Hh} \\
\text { found in some bacteria }\end{array}$ & bacHhN & \\
\hline Bilaterian $\mathrm{Hh}$ & $\mathrm{HhN}$ & $\mathrm{HhC}$ \\
\hline
\end{tabular}

B

$\mathrm{Zn}^{2+}$ coordination/DD-peptidase motif

$\mathrm{Ca}^{2+}$ coordination

Residues in the large $\alpha$-helix mutated in holoprosencephaly
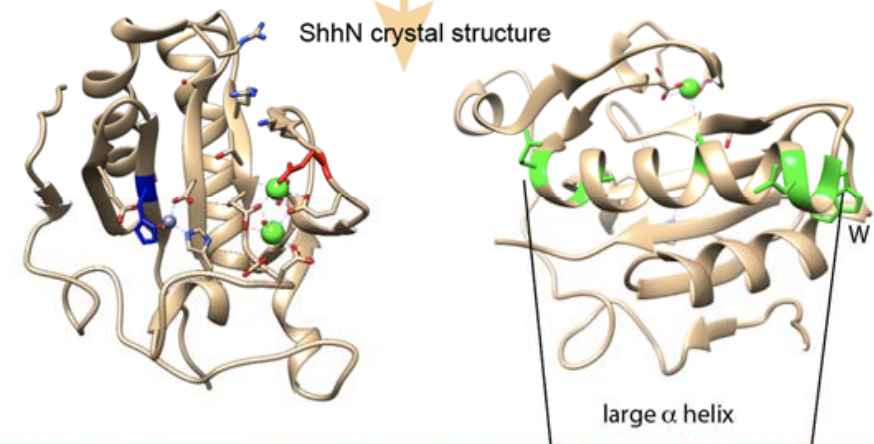

Algibacter LKLKERVPNMKEY--DVVGRISGKILRGTPEF-DELIKNENQKIVFKDEEGTGADHYMTSKLSEKLNLLADLVIQEWGAN 77

Bacillus LNLGEKVPNKKES--DVVGPITGVIQRGNPDE-NTLVRSNNQDIQFKDEEGTGADFLMTSRLSDKLNTLAILVNQEW-PN 76 Bradyrhizobium LTOGQKVPNASET--ATCGAIAKKIKRTDPEF-ATLVSNONASIVFKDEEGTGADRMMSTRLQAKLDALASLVSAEW-AG 76 Pseudonocardia dioxanivorans VPIGEHVPARAEA--DASGAATGVVAAGSPEF-DALVRLDDPTVVVKDEEGSGADRMMTPRLAELVGVLAAHVAQAF-PG 76 Mesorhizobium LSQGQKVPNASEL--VTCGPITKKITRTDPEF-AGLVTNTNAKIVFKDEENTGADRMMTPRLKSKLDSLANVVASEW-PG 76 Micromonospora LS LGERVPNVGEA--SVVGPIAGKVVRGSPEF-NALVKNDNPDIVFKDEEKTDADRMMTPRLRDMVNELAALVVKEW-PG 76 Paenibacillus panacisoli LSVGQKVPDMLESQ--AAGPFT DAVHRGSNEF-KNFVYNNNPLIVYDDEERGHSNHYMTKDLADQLNRLAELVAAEW-SG 76 Pseudoalteromonas piratica LKKGQRWPQSSEIK--SSGEARQTLSGSSLR--DCMNKSANNLPVFKFEEGNFT DVQASEKLCAAIMDLNKLVMKEW-PG 75 spirosoma LTLGQKVPDRAEKDS LASGPFNKAILRGTPEF-ATLVENKNEKVVFKNEEGDGSDRMMTPVLKTHVDRLADLVRSEWgAG 79 Nematostella vectensis hedgling LSQGSSYP-YSKTEVSVCGGIRDVILRNSARF IKILVRNADTEVVFENDDC----RRTTARAKSKLDVLASRVRQEW-AG 74 $\begin{array}{ll}\text { Nematostella Hh1 LYFKQRVPDVDEFS 1 GASGRPQGKITRNSSKF-NKLVACYNT DIVFKDEERTGADRLMSKRCREKLRNLATKVKQKW-KG } & 78 \\ \text { nematostella Hh2 MKIREHI PDTSETS } 1 \text { QASGPSR-KIKRGSNGY-KELITNADPNIVFR-EDKAGNNRRMSKRCERKLKILSSLVRKEW IGD } & 77\end{array}$ Varroa destructor LVVKQYVPNTAEQNeIAAGRAKGAISRTSMAF-RKLVPNYNTDIRFLDDEGTGADRIMTQRCRDKLDTLAVSVMTQW-PG 78

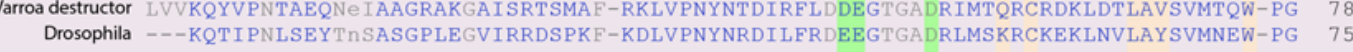
Sperm Whale LAYKQFI PNVAEKTIGASGRYEGKITRNSERF-KELTPNYNPDIIFKDEENTGADRLMTQRCKDKLNALAISVMNQW-PG 78

\begin{tabular}{|c|c|c|c|}
\hline Algibacter & IKLRVTEAWDEDN & EHASK-SIHYEGRGADITTSDRDSSKLGRLARLAVEVGLDWVFY-EDNSHVHVSMKK- & 145 \\
\hline Bacillus & IKLRVTEAWDEDN & EHSSG-STHYEGRAADITTSDRDGNKLGRLAQLAVDAGFDWVYY-ENKYHIHVSVKK- & 144 \\
\hline Bradyrhizobium & VKLRVTEAWDEND & EHLPT-ALHYEGRAADITTQPPDGAKLGRLARLAVNAGCDWVFY-EDTSHVHVSVKKa & 145 \\
\hline Pseudonocardia dioxanivorans & RRLRLTEAWDPDG & EHSHS-SLHYEGRAADLTVDDRDRAKLGRLAALAVQTGFDWVLH-END-HVHVSVRAg & 144 \\
\hline Mesorhizobium & AKLRVTEAWDEDN & EHADA-SLHYEGRAADLTTNPVDGAKLGRLARLAVDAGCDWVFF-EDSSHIHVSVKAg & 145 \\
\hline Micromonospora & KKLRVTEGWDENN & EHTAE-STHYEGRAVDMTVSDLDAAKLGRLARLAVDAGFDWVFY-ENALHVHASVKK- & 144 \\
\hline Paenibacillus panacisoli & IKLMVI DGWSDPD [1] & ] RPPHNnRLYHEGRAADLTVSDLDTSKLGRLGWLAVDAGFDFVHY-ESQDHIHVAVKV- & 146 \\
\hline Pseudoalteromonas piratica & KTLRVTEAYDQDG & EHAKF-SLHNEGRAADMTVSDRDLKKLGRLGFLATKAGFSWVYY -EHN-HIHASVKR- & 142 \\
\hline spirosoma & VSLRVTEAWDDTG & EHSSShSLHYEGRAVDLTTSDLDKSKLGRLGRLAVDAGFNWVYY-ENLLHIHASVTKa & 149 \\
\hline Nematostella vectensis hedgling & RKLKVIKAWTDQR [1] & I AQDPA-SLHYEGRALRLQLDNNDRSMLSRLAGLALASGFDWVSYPLNSDYIHASVIR- & 144 \\
\hline Nematostella Hh1 & VKLRVTEAWDEDG & QHSLD-SLHYEGRAVDISTSDKDPKKLPDLGSLAVDAGFDWVYY-DRRSSIHASVRS- & 146 \\
\hline nematostella Hh2 & VKVRVIRAYDDGT [4] & ] HHGPH-SLHF SGRALDITTSDEKRDKLPMLGRLAYRAGFDWV-Y-RAKAYIHASVKS- & 148 \\
\hline Varroa destructor & VKLRVIESWDEYS & HHKSG-SLHYEGRAVDFTTDDRHQAKYGMLARLAVEAGFDWVYY-ETKRHVHASVKP- & 146 \\
\hline Drosophila & IRLLVTESWDEDY & HHGQE-SLHYEGRAVTIATSDRDQSKYGMLARLAVEAGFDWVSY-VSRRHIYCSVKS- & 143 \\
\hline Sperm Whale & VKLRVTEGWDEDG & HHSEE-SLHYEGRAVDITTSDRDRSKYGMLARLAVEAGFDWVYY-ESKAHIHCSVKA- & 146 \\
\hline \multicolumn{2}{|c|}{ Bacterial Hh/DD-peptidases } & Hedgehogs & \\
\hline
\end{tabular}

Figure 4. The Hh/DD-peptidase family. (A) Diagram of the structure of the DD-peptidases in bacteria and animals. In bacteria, the peptidases are the C-terminal domains of larger proteins. In all cases, the peptidase domain is predicted to be located in the periplasmic space. In Rhizobium $\mathrm{Hh}$, the third transmembrane domain (red) is at the same position as the signal sequence in metazoan $\mathrm{Hh}$ (red). (B) Lineup of the Hh/DD-peptidase domains of bacteria (green background), Hedgling (salmon background) and Hhs (purple background). Mutations in the $\mathrm{Zn}^{2+}$ coordinating/DD-peptidase motif defining residues in Hedgling and Drosophila Hh are indicated in bold. The blue columns indicate residues involved in $\mathrm{Zn}^{2+}$ coordination and define the DD-peptidase motif; the green columns indicate residues involved in $\mathrm{Ca}^{2+}$ binding. Varroa is typical for all non-Drosophilid insects. Aligned sequences are in the Supplementary file. 


\section{What Are the Possible Substrates for the Shh Peptidase Activity?}

The general properties of bacterial DD-peptidases and lysostaphins as modifiers of the bacterial cell wall are likely shared with the bacHhs. The peptidoglycans that are a major component of the bacterial periplasmic space have some similarities to the proteoglycans that are common in the insect and vertebrate extracellular matrix. Both bacterial cell wall peptidoglycans and animal matrix proteoglycans are large molecules in which polypeptides are covalently attached to chains of glycans. In particular, the matrix heparin sulfate proteoglycans (HSPGs) bind Shh and can both negatively and positively affect the Shh response [30-32]. Furthermore, mutations in ext genes that code for glycosyltransferases that catalyze glycosaminoglycan in addition to the core protein disrupt $\mathrm{Hh}$ signaling in vertebrates [33] and insects [34]. It is thus possible that functional conservation between bacHhs and Shh is reflected in the ability of Shh to cleave or modify proteoglycans, thus affecting the Shh response or distribution, independent of binding to the canonical receptors.

Although any Shh antagonist could be a possible target for Shh peptidase activity, both Hhip and Ptch1 are unlikely substrates, as they have the characteristics of metalloprotease inhibitors [19].

\section{Drosophila Hh Is Not a Member of the Hh/DD-Peptidase Family}

Drosophila $\mathrm{Hh}(\mathrm{dmHh})$ has been the guide molecule for all Hh signaling since the discovery that it is necessary for embryogenesis [1]. However, dmHh is unusual in that is does not have the core sequences H-X(6)-D, H-X-H that define the Hh/DD-peptidase motif, but instead, dmHh has H-X(6)-T, H-X-Y. Furthermore, the catalytically important E177 (mouse numbering) is mutated in $\mathrm{dmHh}$ into a valine residue. The absence of the $\mathrm{Hh} / \mathrm{DD}$-peptidase motif is unique to all sequenced Drosophilids; searching with the Drosophila sequence that encompasses the DD-peptidase motif (ESLHYEGRAVTIATSDRDQSKYGMLARLAVEAGFDWVSYVSRRHIYCSVKS) places Drosophilids as an outgroup to all other arthropods and deuterostomes. Drosophilids are the outlier because Hh proteins in all other protostomes and deuterostomes retain the conserved Hh/DD-peptidase $\mathrm{Zn}^{2+}$ coordination motif. Searching with a hypothetical $d m H h$ peptide that conforms to the Hh/DD-peptidase motif and E177 does no longer uniquely group with the Drosophilids, and has similar homology to several vertebrate and insect Hhs. Given the high degree of $\mathrm{HhN}$ conservation between bacteria and eukaryotes (Figure 3), the most plausible explanation for this is that Drosophilids have lost some of the activities associated with the ancestral $\mathrm{Zn}^{2+}$ coordination domain. The loss of $\mathrm{Zn}^{2+}$ coordinating residues in conjunction with the E177 homolog is no surprise in light of the likely loss of peptidase activity in Drosophila Hh. The observation that vertebrate Shh is active in Drosophila embryos [35], but Drosophila $H h$ is not active in vertebrates, further supports the notion that some aspects of Hh signaling present in most animals are lost in fruit flies, but that both proteins can bind to Ptch. These observations question to what extent the lessons learned in Drosophila embryos regarding Hh processing and signaling can be directly applied to vertebrates, or even other arthropods, as all these animals maintain an intact Hh/DD-peptidase domain. The study of Hh signaling in another insect, such a Tribolium [36], might help to resolve how Drosophila Hh signaling is impacted by the loss of the DD-peptidase motif in the ligand.

\section{The Presence of bacHhs Suggests an Alternative Hypothesis Regarding the Evolution of Modern Hh}

Hh genes are present in Cnidarians (corals and jellyfish), but not in sponges and protozoa [37]. However, another class of proteins that contain an N-terminal HhN-like domain is the Hedgling proteins that can be found in Cnidarians, sponges and Choanoflagellates [38], which are protozoans. In these Hedgling proteins, the $\mathrm{HhN}$ domain is followed by a large C-terminal domain that is related to cell adhesion molecules. A plausible evolutionary path is that the $\mathrm{HhN}$ domain of Hedgling was recombined to a Hog domain that is present in most genomes (Figure 5 green arrows). However, the HhN domain of Hedgling does not contain a complete Hh/DD-peptidase motif, whereas, it is likely that its putative ancestral form in the last universal common ancestor (LUCA) had an intact 
Hh/DD-peptidase domain. Although this evolutionary path from a LUCA DD-peptidase via Hedgling to Hh could have conceivably occurred without horizontal gene transfer (Figure 5, green arrows), it would have required several recombination events. The first event would have entailed the recombination of the bacterial-like Hh domain from a DD-peptidase to form the Hedgling protein, and the second event would have involved recombination of the HhN domain of Hedgling into modern Hh. Following this potential evolutionary path, the Hh/DD-peptidase motif would have been lost in Hedgling and re-established in Hh.

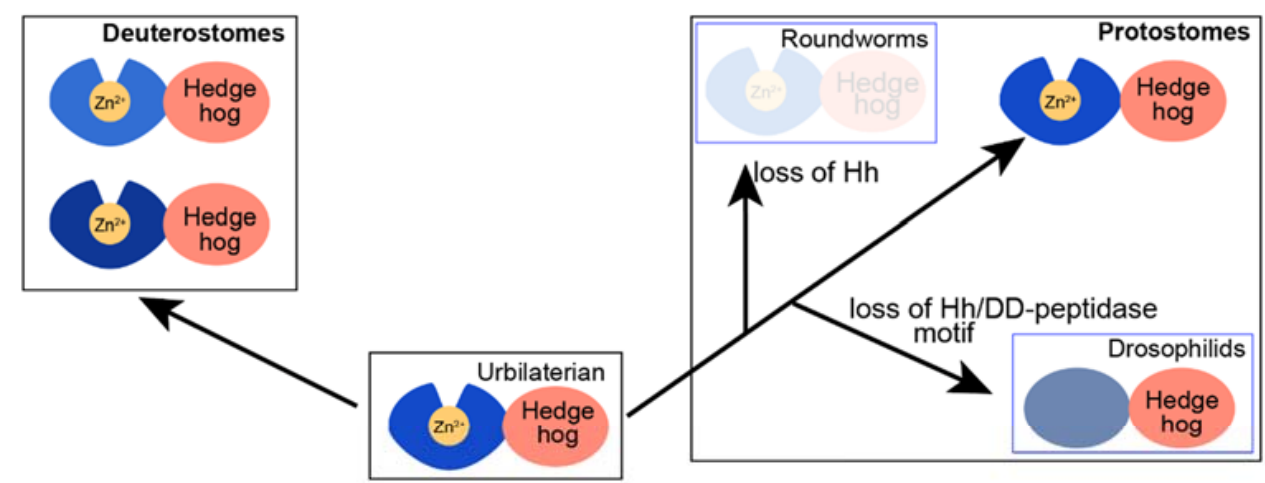

Hh evolution via protozoan Hedgling Hh evolution via horizontal gene transfer from a bacterium to a Cnidarian

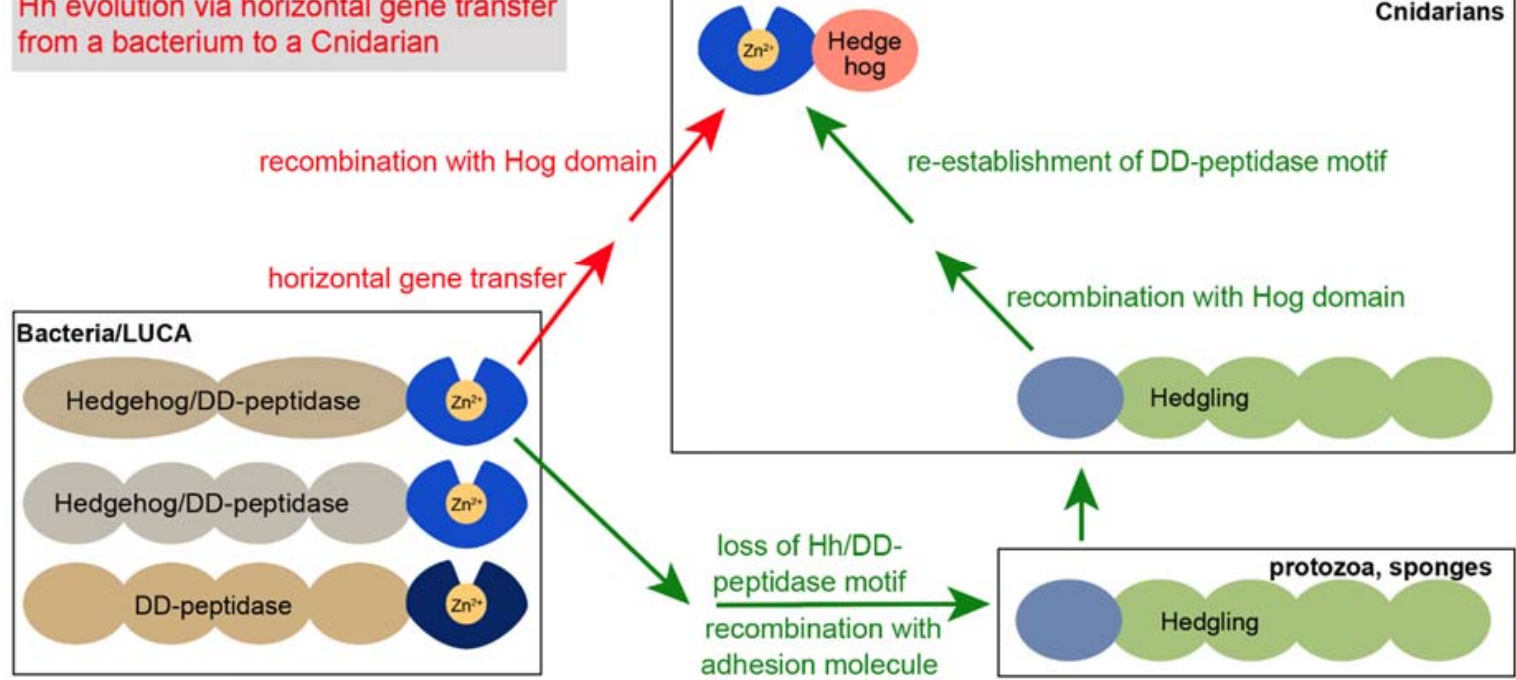

Figure 5. Models for the evolution of modern Hh proteins. The presence of both Hhs and Hedglings in Cnidarians support the model that the $\mathrm{HhN}$ of $\mathrm{Hh}$ domain arose via a recombination of the Hedgling $\mathrm{N}$-domain. As Hedgling is present in at least some protozoa, it is plausible that it was derived from a DD-peptidase in the last universal common ancestor (LUCA). Alternatively, a Hh/DD-peptidase could have entered a Cnidarian ancestor from a bacterium via horizontal gene transfer, never losing the $\mathrm{Zn}^{2+}$ coordination in the process. Modern Hh was present in the Urbilaterian (the last common ancestor of protostomes and deuterostomes) and was retained in most of its offspring. The loss of the Hh/DD-peptidase motif in Drosophilids is derived, as is the loss of all Hh in some bilaterian protostomes (such as roundworms).

The presence of highly conserved $\mathrm{HhN}$ protein domains in bacteria suggests an alternate hypothesis, in which horizontal bacHh//DD-peptidase gene transfer from a bacterium to a Cnidarian ancestor was followed by recombination of the HhN domain with a Cnidarian Hog domain, resulting in a modern Hh gene (Figure 5, red arrows). This possible evolutionary path would have required only one recombination event and would not have involved the subsequent loss and re-establishment 
of the Hh/DD-peptidase domain, as is indicated for the evolutionary path via Hedgling. As the more parsimonious explanation it is perhaps a more plausible path for the evolution of modern $\mathrm{Hh}$. The higher conservation between ShhN and bacterial Hh/DD-peptidases than between ShhN and the $\mathrm{N}$-domain of Hedgling lends further support to the horizontal gene transfer model.

\section{Conclusions}

Although the $\mathrm{Zn}^{2+}$ coordination domain of Shh is often referred to as its "pseudo catalytic" domain $[19,39,40]$, the remarkable similarity of most Hhs to bacterial Hh/DD-peptidases further supports the notion that Shh functions as a peptidase during development. Some mutations found in holoprosencephaly patients break the Hh/DD-peptidase motif, and negatively affect Hh signaling, possibly by preventing autoproteolytic cleavage, indicating that the intrinsic $\mathrm{Zn}^{2+}$ peptidase activity of Shh is critical to its function. The lack of the Hh/DD-peptidase domain in Drosophila Hh demonstrates that it is evolutionary derived, and perhaps not the best model for Hh signaling in animals with the ancestral Hh/DD-peptidase motif, like humans and mice. Finally, the presence of HhN protein domains in some bacteria supports an alternate pathway for the evolution of $\mathrm{Hh}$, via horizontal gene transfer from bacteria into an Urbilaterian ancestor, resulting in the modern Hh which has retained ancestral peptidase activity.

Supplementary Materials: The following are available online at http:/ /www.mdpi.com/2221-3759/6/2/12/s1.

Funding: This research was funded by NIGMS grant number R01GM117090.

Conflicts of Interest: The author declares no conflict of interest.

\section{References}

1. Nüsslein-Volhard, C.; Wieshaus, E. Mutations affecting segment number and polarity in Drosophila. Nature 1980, 287, 795-801. [CrossRef] [PubMed]

2. Echelard, Y.; Epstein, D.J.; St-Jacques, B.; Shen, L.; Mohler, J.; McMahon, J.A.; McMahon, A.P. Sonic hedgehog, a member of a family of putative signaling molecules, is implicated in the regulation of CNS polarity. Cell 1993, 75, 1417-1430. [CrossRef]

3. Hall, T.M.; Porter, J.A.; Beachy, P.A.; Leahy, D.J. A potential catalytic site revealed by the 1.7-A crystal structure of the amino-terminal signalling domain of Sonic hedgehog. Nature 1995, 378, 212-216. [CrossRef] [PubMed]

4. Rebollido-Rios, R.; Bandari, S.; Wilms, C.; Jakuschev, S.; Vortkamp, A.; Grobe, K.; Hoffmann, D. Signaling domain of Sonic Hedgehog as cannibalistic calcium-regulated zinc-peptidase. PLoS Comput. Biol. 2014, 10, e1003707. [CrossRef] [PubMed]

5. Porter, J.A.; Ekker, S.C.; Park, W.J.; von Kessler, D.P.; Young, K.E.; Chen, C.H.; Ma, Y.; Woods, A.S.; Cotter, R.J.; Koonin, E.V.; et al. Hedgehog patterning activity: Role of a lipophilic modification mediated by the carboxy-terminal autoprocessing domain. Cell 1996, 86, 21-34. [CrossRef]

6. Porter, J.A.; Young, K.E.; Beachy, P.A. Cholesterol modification of hedgehog signaling proteins in animal development. Science 1996, 274, 255-259. [CrossRef] [PubMed]

7. Taylor, F.R.; Wen, D.; Garber, E.A.; Carmillo, A.N.; Baker, D.P.; Arduini, R.M.; Williams, K.P.; Weinreb, P.H.; Rayhorn, P.; Hronowski, X.; et al. Enhanced potency of human Sonic hedgehog by hydrophobic modification. Biochemistry 2001, 40, 4359-4371. [CrossRef] [PubMed]

8. Pepinsky, R.B.; Zeng, C.; Wen, D.; Rayhorn, P.; Baker, D.P.; Williams, K.P.; Bixler, S.A.; Ambrose, C.M.; Garber, E.A.; Miatkowski, K.; et al. Identification of a palmitic acid-modified form of human Sonic hedgehog. J. Biol. Chem. 1998, 273, 14037-14045. [CrossRef] [PubMed]

9. Chamoun, Z.; Mann, R.K.; Nellen, D.; von Kessler, D.P; Bellotto, M.; Beachy, P.A.; Basler, K. Skinny hedgehog, an acyltransferase required for palmitoylation and activity of the hedgehog signal. Science 2001, 293, 2080-2084. [CrossRef] [PubMed]

10. Tukachinsky, H.; Kuzmickas, R.P.; Jao, C.Y.; Liu, J.; Salic, A. Dispatched and scube mediate the efficient secretion of the cholesterol-modified hedgehog ligand. Cell Rep. 2012, 2, 308-320. [CrossRef] [PubMed] 
11. Roelink, H.; Porter, J.A.; Chiang, C.; Tanabe, Y.; Chang, D.T.; Beachy, P.A.; Jessell, T.M. Floor plate and motor neuron induction by different concentrations of the amino-terminal cleavage product of sonic hedgehog autoproteolysis. Cell 1995, 81, 445-455. [CrossRef]

12. Ohlig, S.; Farshi, P.; Pickhinke, U.; van den Boom, J.; Höing, S.; Jakuschev, S.; Hoffmann, D.; Dreier, R.; Schöler, H.R.; Dierker, T.; et al. Sonic hedgehog shedding results in functional activation of the solubilized protein. Dev. Cell 2011, 20, 764-774. [CrossRef] [PubMed]

13. Hall, T.M.; Porter, J.A.; Young, K.E.; Koonin, E.V.; Beachy, P.A.; Leahy, D.J. Crystal structure of a Hedgehog autoprocessing domain: Homology between Hedgehog and self-splicing proteins. Cell 1997, 91, 85-97. [CrossRef]

14. Tokhunts, R.; Singh, S.; Chu, T.; D'Angelo, G.; Baubet, V.; Goetz, J.A.; Huang, Z.; Yuan, Z.; Ascano, M.; Zavros, Y.; et al. The full-length unprocessed hedgehog protein is an active signaling molecule. J. Biol. Chem. 2010, 285, 2562-2568. [CrossRef] [PubMed]

15. Traiffort, E.; Dubourg, C.; Faure, H.; Rognan, D.; Odent, S.; Durou, M.-R.; David, V.; Ruat, M. Functional characterization of sonic hedgehog mutations associated with holoprosencephaly. J. Biol. Chem. 2004, 279, 42889-42897. [CrossRef] [PubMed]

16. Inouye, K.; Kusano, M.; Hashida, Y.; Minoda, M.; Yasukawa, K. Engineering, expression, purification, and production of recombinant thermolysin. Biotechnol. Annu. Rev. 2007, 13, 43-64. [PubMed]

17. Zeng, X.; Goetz, J.A.; Suber, L.M.; Scott, W.J.J.; Schreiner, C.M.; Robbins, D.J. A freely diffusible form of Sonic hedgehog mediates long-range signalling. Nature 2001, 411, 716-720. [CrossRef] [PubMed]

18. Fuse, N.; Maiti, T.; Wang, B.; Porter, J.A.; Hall, T.M.; Leahy, D.J.; Beachy, P.A. Sonic hedgehog protein signals not as a hydrolytic enzyme but as an apparent ligand for patched. Proc. Natl. Acad. Sci. USA 1999, 96, 10992-10999. [CrossRef] [PubMed]

19. Bosanac, I.; Maun, H.R.; Scales, S.J.; Wen, X.; Lingel, A.; Bazan, J.F.; de Sauvage, F.J.; Hymowitz, S.G.; Lazarus, R.A. The structure of SHH in complex with HHIP reveals a recognition role for the Shh pseudo active site in signaling. Nat. Struct. Mol. Biol. 2009, 16, 691-697. [CrossRef] [PubMed]

20. Maun, H.R.; Wen, X.; Lingel, A.; de Sauvage, F.J.; Lazarus, R.A.; Scales, S.J.; Hymowitz, S.G. Hedgehog pathway antagonist 5E1 binds hedgehog at the pseudo-active site. J. Biol. Chem. 2010, 285, 26570-26580. [CrossRef] [PubMed]

21. Odent, S.; Atti Bitach, T.; Blayau, M.; Mathieu, M.; Aug, J.; Delezo de, A.L.; Gall, J.Y.; Le Marec, B.; Munnich, A.; David, V.; et al. Expression of the Sonic hedgehog (SHH) gene during early human development and phenotypic expression of new mutations causing holoprosencephaly. Hum. Mol. Genet. 1999, 8, 1683-1689. [CrossRef] [PubMed]

22. Hehr, U.; Pineda-Alvarez, D.E.; Uyanik, G.; Hu, P.; Zhou, N.; Hehr, A.; Schell-Apacik, C.; Altus, C.; Daumer-Haas, C.; Meiner, A.; et al. Heterozygous mutations in SIX3 and SHH are associated with schizencephaly and further expand the clinical spectrum of holoprosencephaly. Hum. Genet. 2010, 127, 555-561. [CrossRef] [PubMed]

23. Roessler, E.; El-Jaick, K.B.; Dubourg, C.; Vélez, J.I.; Solomon, B.D.; Pineda-Alvarez, D.E.; Lacbawan, F.; Zhou, N.; Ouspenskaia, M.; Paulussen, A.; et al. The mutational spectrum of holoprosencephaly-associated changes within the SHH gene in humans predicts loss-of-function through either key structural alterations of the ligand or its altered synthesis. Hum. Mutat. 2009, 30, E921-E935. [CrossRef] [PubMed]

24. Day, E.S.; Wen, D.; Garber, E.A.; Hong, J.; Avedissian, L.S.; Rayhorn, P.; Shen, W.; Zeng, C.; Bailey, V.R.; Reilly, J.O.; et al. Zinc-dependent structural stability of human Sonic hedgehog. Biochemistry 1999, 38, 14868-14880. [CrossRef] [PubMed]

25. Hitzenberger, M.; Schuster, D.; Hofer, T.S. The Binding Mode of the Sonic Hedgehog Inhibitor Robotnikinin, a Combined Docking and QM/MM MD Study. Front. Chem. 2017, 5, 76. [CrossRef] [PubMed]

26. Stanton, B.Z.; Peng, L.F.; Maloof, N.; Nakai, K.; Wang, X.; Duffner, J.L.; Taveras, K.M.; Hyman, J.M.; Lee, S.W.; Koehler, A.N.; et al. A small molecule that binds Hedgehog and blocks its signaling in human cells. Nat. Chem. Biol. 2009, 5, 154-156. [CrossRef] [PubMed]

27. Himmelstein, D.S.; Cajigas, I.; Bi, C.; Clark, B.S.; Van Der Voort, G.; Kohtz, J.D. SHH E176/E177-Zn(2+) conformation is required for signaling at endogenous sites. Dev. Biol. 2017, 424, 221-235. [CrossRef] [PubMed]

28. Van Heijenoort, J. Peptidoglycan hydrolases of Escherichia coli. Microbiol. Mol. Biol. Rev. 2011, 75, 636-663. [CrossRef] [PubMed]

29. Bochtler, M.; Odintsov, S.G.; Marcyjaniak, M.; Sabala, I. Similar active sites in lysostaphins and D-Ala-D-Ala metallopeptidases. Protein Sci. 2004, 13, 854-861. [CrossRef] [PubMed] 
30. Carrasco, H.; Olivares, G.H.; Faunes, F.; Oliva, C.; Larraín, J. Heparan sulfate proteoglycans exert positive and negative effects in Shh activity. J. Cell. Biochem. 2005, 96, 831-838. [CrossRef] [PubMed]

31. Capurro, M.I.; Xu, P.; Shi, W.; Li, F.; Jia, A.; Filmus, J. Glypican-3 inhibits Hedgehog signaling during development by competing with patched for Hedgehog binding. Dev. Cell 2008, 14, 700-711. [CrossRef] [PubMed]

32. Witt, R.M.; Hecht, M.-L.; Pazyra-Murphy, M.F.; Cohen, S.M.; Noti, C.; van Kuppevelt, T.H.; Fuller, M.; Chan, J.A.; Hopwood, J.J.; Seeberger, P.H.; et al. Heparan sulfate proteoglycans containing a glypican 5 core and 2-O-sulfo-iduronic acid function as Sonic Hedgehog co-receptors to promote proliferation. J. Biol. Chem. 2013, 288, 26275-26288. [CrossRef] [PubMed]

33. Siekmann, A.F.; Brand, M. Distinct tissue-specificity of three zebrafish ext1 genes encoding proteoglycan modifying enzymes and their relationship to somitic Sonic hedgehog signaling. Dev. Dyn. 2005, 232, 498-505. [CrossRef] [PubMed]

34. Bellaiche, Y.; The, I.; Perrimon, N. Tout-velu is a Drosophila homologue of the putative tumour suppressor EXT-1 and is needed for Hh diffusion. Nature 1998, 394, 85-88. [PubMed]

35. Krauss, S.; Concordet, J.P.; Ingham, P.W. A functionally conserved homolog of the Drosophila segment polarity gene hh is expressed in tissues with polarizing activity in zebrafish embryos. Cell 1993, 75, 1431-1444. [CrossRef]

36. Villarreal, C.M.; Darakananda, K.; Wang, V.R.; Jayaprakash, P.M.; Suzuki, Y. Hedgehog signaling regulates imaginal cell differentiation in a basally branching holometabolous insect. Dev. Biol. 2015, 404, 125-135. [CrossRef] [PubMed]

37. Adamska, M.; Matus, D.Q.; Adamski, M.; Green, K.; Rokhsar, D.S.; Martindale, M.Q.; Degnan, B.M. The evolutionary origin of hedgehog proteins. Curr. Biol. 2007, 17, R836-R837. [CrossRef] [PubMed]

38. Fairclough, S.R.; Chen, Z.; Kramer, E.; Zeng, Q.; Young, S.; Robertson, H.M.; Begovic, E.; Richter, D.J.; Russ, C.; Westbrook, M.J.; et al. Premetazoan genome evolution and the regulation of cell differentiation in the choanoflagellate Salpingoeca rosetta. Genome Biol. 2013, 14, R15. [CrossRef] [PubMed]

39. Pettigrew, C.A.; Asp, E.; Emerson, C.P. A new role for Hedgehogs in juxtacrine signaling. Mech. Dev. 2014, 131, 137-149. [CrossRef] [PubMed]

40. Ochi, H.; Pearson, B.J.; Chuang, P.-T.; Hammerschmidt, M.; Westerfield, M. Hhip regulates zebrafish muscle development by both sequestering Hedgehog and modulating localization of Smoothened. Dev. Biol. 2006, 297, 127-140. [CrossRef] [PubMed] 